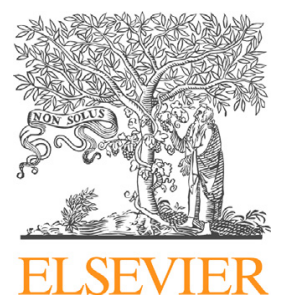

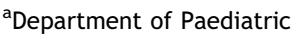
Urology, Royal Manchester Children's Hospital, UK

bInstitute of Surgical Research, School of Medicine, University of Szeged, Hungary

'Department of Paediatric Surgery, Royal Manchester Children's Hospital, UK

Correspondence to: T. Cserni, Department of Paediatric Urology, Royal Manchester Children's Hospital, UK

tcserni@yahoo.com

(T. Cserni)

\section{Keywords}

Mucosectomy; lleocystoplasty;

In vivo microscopy;

Microcirculation

Received 1 June 2016

Accepted 3 November 2016

Available online 29 November 2016

\title{
Mucosectomy impairs ileal microcirculation and results in flap contraction after experimental ileocystoplasty
}

\author{
Raimondo M. Cervellione ${ }^{\mathrm{a}, \mathrm{b}}$, Daniel Hajnal ${ }^{\mathrm{b}}$, Gabreilla Varga ${ }^{\mathrm{b}}$, \\ George Rakoczy ${ }^{\mathrm{c}}$, Jozsef Kaszaki ${ }^{\mathrm{b}}$, David Keene ${ }^{\mathrm{a}}$, Anju Goyal ${ }^{\mathrm{a}}$, \\ Alan Dickson ${ }^{a}$, Tamas Cserni ${ }^{\text {a,b }}$
}

\section{Summary}

\section{Introduction}

Bladder augmentation with demucosalized ileal flap is a promising alternative approach for mucus free bladder augmentation; however, the contraction of the flap is still a major concern. It has been hypothesized that mucosectomy causes ischemic damage, but no direct histological evidence has been found and attention is now focused on the urothelium cover to prevent the exposure of the denuded surface to urine or the use of balloons to keep the flaps distended.

\section{Objective}

Our aim was to study the effect of mucosectomy on the microcirculation of ileal flaps during reverse clam ileocystoplasty using direct intraoperative imaging of the ileum. Since the omentum is successfully used to revascularize ischemic tissue, we also examined whether omentopexy can prevent contraction.

\section{Study design}

Clam ileocystoplasty was performed in anesthetized minipigs with seromuscular $(n=3)$, seromusculosubmucosal $(n=3)$ reverse demucosalized ileal flaps. The velocity of the circulating red blood cells (RBCV) and the perfusion rate (PR) was measured with intravital videomicroscopy (Cytoscan A/R, Cytometrics, Philadelphia, PA, USA) before and after mucosectomy and the denuded surface of the ileum was covered with omentum after the reverse augmentation was complete (Figure). Animals were sacrificed after 8 weeks and the ileal flap dimensions were measured.

\section{Results}

Significant reduction in RBCV and PR was detected after mucosectomy in both groups; however, no sign of acute flap necrosis or bladder perforation was seen. The omentum was found firmly attached to the ileal flaps, but contraction of the flaps was significant in both groups.

\section{Conclusion}

The disturbance in the microcirculation observed after mucosectomy may be responsible for flap contraction in ileocystoplasty with demucosalized ileum. Omentopexy did not help to prevent contraction.

\section{Discussion}

Contraction of demucosalized intestinal flaps used for bladder augmentation has been frequently reported. This study provides direct evidence the first time for severely compromised microcirculation of the ileal flaps after mucosectomy. Limitation of the study is the relative low number of animals sacrificed.

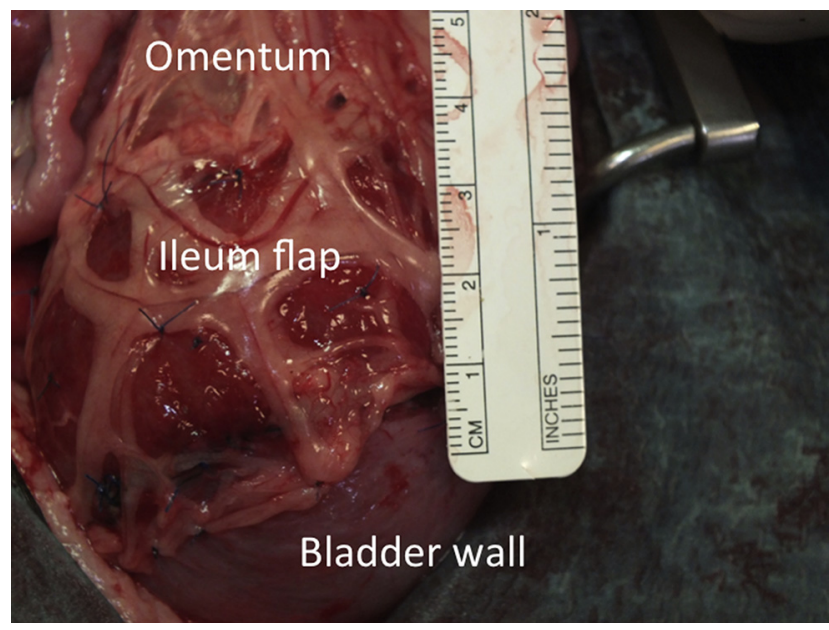

Figure Augmented bladder with reverse sero-musculo-submucosal ileal flap covered with the omentum. 


\section{Introduction}

The presence of intestinal mucosa within the augmented bladder is associated with significant complication risks such as increased infection rate due to mucus production, associated stone formation, absorption of electrolytes from the urine, and potential adenocarcinoma development [1].

William Shoemaker and his colleagues were awarded with the first prize on the essay competition of the American Urological Association in 1955 for the idea of using mucosectomized reversed ileal flaps for bladder augmentation in dogs following subtotal cystectomy [2,3]. It seemed that the intestinal mucosa-related complications would no longer be a concern after mucosectomized reversed flap bladder augmentation. The technique was then applied in four patients; however contraction of the flaps occurred and the technique was abandoned [4]. Thirty years later Oesch [5] revised this procedure and reported no contraction and full epithelization of the caecal segment in rats after mucosectomy. Salle et al. [6] were, however, not able to reproduce these good results in dogs with clam ileo- or colocystoplasty. Reverse flap augmentation was abandoned believing that vascular compromise of the flaps during the procedure may have led to contraction, however no direct evidence was found to support this theory.

Research was focused on non-reversed flaps, but contraction of the flap remained a major concern. Motley et al. [7] performing seromuscular cup shape sigmoid cystoplasty paid special attention to vascular histology, and did not find evidence of vascular thrombosis. Salle et al. [8] concluded that vascular compromise may not play a role in flap contraction after observing in rabbits that seromuscular segments of gastric fundus fixed to the anterior abdominal wall did not contract. The idea of vascular compromise has been refuted.

It has been hypothesized that the tissue contraction may be due to the exposure of the denuded intestinal surface to urine and/or prolonged postoperative decompression of the augmented bladder; therefore, research has been focused on the role of urothelium coverage of the denuded surface and the use of splints to prevent the effect of long-term drainage leading to collapse of the augmented bladder [9-11]. To some extent these varying approaches have led to acceptable results; nevertheless, the contraction of the intestinal flaps still remains a major concern.

We found it interesting that Cheng et al. [12] reported no contraction of a full thickness (intact mucosa) ileal flap used for reverse flap augmentation in a dog. This gave us the idea to review the experience with reverse flap augmentation to find out if mucosectomy has significant effect on the microcirculation of the ileal flaps during reverse clam ileocystoplasty. Since the omentum has been used clinically to promote revascularization and healing of ischemic tissues [13-16] we also examined whether omentopexy prevents the contraction.

\section{Material and methods}

The experiments were performed according to EU Directive 2010/63/EU on the protection of animals used for experimental and other scientific purposes and carried out in strict adherence to the NIH guidelines for the use of experimental animals. The study was approved by the $\mathrm{Na}$ tional Scientific Ethical Committee on Animal Experimentation, with the license number V./1637/2013.

The study was performed on anaesthetized female Vietnamese mini pigs ( $n=6$; weight, $25-30 \mathrm{~kg}$ ). The animals were kept under conventional circumstances, in standard cages, were fed with commercially available mixed food, were fasted $24 \mathrm{~h}$ before surgery and always had free access to water. Anaesthesia was induced with an intramuscular injection of a mixture of ketamine $(20 \mathrm{mg} /$ $\mathrm{kg})$ and xylazine $(2 \mathrm{mg} / \mathrm{kg})$ and maintained with a continuous infusion of propofol (2\%; $50 \mu \mathrm{L} / \mathrm{kg} / \mathrm{min}$ i.v.) via a cannulated ear vein. An endotracheal tube was inserted and the animals were ventilated mechanically with a volume-controlled ventilator. The tidal volume was set at 8-9 $\mathrm{mL} / \mathrm{kg}$, and the respiratory rate was adjusted to maintain the end tidal carbon dioxide pressure $\left(\mathrm{EtCO}_{2}\right)$ between 35 and $45 \mathrm{mmHg}$. Norocarp S (carprofen; $4 \mathrm{mg} / \mathrm{kg}$ ) and normal saline infusion were administered via an ear vein catheter. Hearth rate, $\mathrm{O}_{2}$ saturation (pulseoxymetry), $\mathrm{EtCO}_{2}$ (capnometry) and body temperature were continuously monitored perioperatively.

Clam ileocystoplasty was performed using $15-\mathrm{cm}$-long ileum segments in two groups. First the ileal segment was isolated and detubularized along the paramesenteric line. The bowel was kept warm with $0.9 \%$ saline solution. The detubularized bowel strips were placed on wet gauze and the width was measured with a linear ruler under no tension and the microcirculation was recorded on the serosal surface.

Then mucosectomy was applied. In the seromuscular group the mucosa and the submucosa were peeled from the seromuscular layer in one piece. It was easy to separate the submucosa from the muscular layers at one corner of the flap with fine forceps. Injection of saline into the submucosa was not necessary. In the seromusculo-submucosal group only the mucosa was scraped from the bowel with the back of forceps at the level of the mucosa propria. Surgical loops with $2.5 \times$ magnification was used to make sure no mucosa islands left behind. The microcirculation was rerecorded in each group after the mucosectomy procedure on the serosal surface. Clam ileocystoplasty was performed in each group with the serosa facing inside (reverse fashion), with non-absorbable 4/0 Prolene sutures. The denuded surface of the ileal flap facing the abdominal cavity was covered with the omentum in both groups, and anchored by $4 / 0$ polysorb sutures. Malecot catheters (12F) were left in the urethra, the tip of the catheters being fixed with 5/0 Polysorb to the bladder mucosa. The end of the catheters needed to be cut at the level of the external urethral meatus since the animals do not tolerate catheters hanging out of their body; they were sutured to the labia minora with 5/0 Polysorb to keep them in situ for 5-7 days.

The intravital orthogonal polarization spectral imaging technique (Cytoscan A/R, Cytometrics, Philadelphia, PA, USA) was used for visualization of the microcirculation of the intestinal serosa. This technique utilizes reflected polarized light at the wavelength of the isobestic point of oxy- and deoxyhaemoglobin $(548 \mathrm{~nm})$. As polarization is preserved in reflection, only photons scattered from a depth of $2-300 \mu \mathrm{m}$ contribute to image formation. A $10 \times$ 
objective was positioned on the surface of intestine, and the microscopic images were recorded with an S-VHS video recorder (Panasonic AG-TL 700; Matsushita Electric Ind. Co. Ltd, Osaka, Japan). Microcirculatory evaluation was performed off-line by frame-to-frame analysis of the videotaped images. The capillary red blood cell velocity (RBCV) and the perfusion rate (PR) changes in the capillaries were determined before and after mucosectomy on the serosal surface, in three randomly selected separate fields in the middle of the flaps by means of a computer-assisted image analysis system (IVM Pictron, Budapest, Hungary). All microcirculatory evaluations were performed by one investigator (G.V.).

Data analysis was performed with a statistical software package (SigmaStat for Windows; Jandel Scientific, Germany). The Wilcoxon rank sum test was applied for withingroup analysis. Differences between groups were analysed the with Mann-Whitney test. Median values, and 75th and 25 th percentiles are given. A $p$ values $<0.05$ was considered significant.

The animals were sacrificed after 8 weeks. The bladder was removed, and opened, and the non-absorbable suture line was identified and the ileal flap dimensions were measured. The Shapiro-Wilk normality test and paired $t$ test were applied. Means and standard deviation are given. A $p$ value $<0.05$ was considered significant.

\section{Results}

The mean width of the detubularized ileum was $37 \pm 1 \mathrm{~mm}$ at pre-augmentation in the animals (Table 1 ).

Significant reductions in RBCV and PR were detected after mucosectomy in both mucosectomy groups (Fig. 1).
Table 1 Dimension of ileal flaps pre- and postaugmentation.

\begin{tabular}{|c|c|c|}
\hline Pre-augmentation & Post-augmenta & \\
\hline $\begin{array}{l}\text { Mean ileal } \\
\text { flap width }\end{array}$ & $\begin{array}{l}\text { Sero-musculo- } \\
\text { submucosal } \\
\text { flap width }\end{array}$ & $\begin{array}{l}\text { Sero-muscular } \\
\text { ileal flap } \\
\text { width }\end{array}$ \\
\hline $37+/-1 \mathrm{~mm}$ & $20+1-2 \mathrm{~mm}$ & $16+/-2 \mathrm{~mm}$ \\
\hline
\end{tabular}

The animals recovered very quickly after the operation. They were kept on liquid food for 3-4 days then fed normally. They were not lethargic and no loss off appetite was observed and their wound healed well. They passed the catheter in 5-7 days. No complications like peritonitis or ascites were seen. At the autopsy no perforation or necrosis was seen. The average width of the ileum measured after autopsy was $16 \pm 2 \mathrm{~mm}$ in the seromuscular group, and $20 \pm 2 \mathrm{~mm}$ in the seromusculo-submucosal group (Table 1). The omentum was found firmly attached to the ileal flaps; however, significant $(p<0.05)$ contraction of the flaps had developed in both groups (Fig. 2).

\section{Discussion}

With the spread of minimally invasive endoscopic submucosal dissection (ESD) technique for removal of gastrointestinal mucosal malignancies, there is more indirect evidence that oesophageal, gastric, and colorectal stricture occurs after surgical manipulation of the submucosa, especially after ESD of large lateral spreading tumours occupying $75 \%$ of the lumen $[17,18]$. Further evidence of
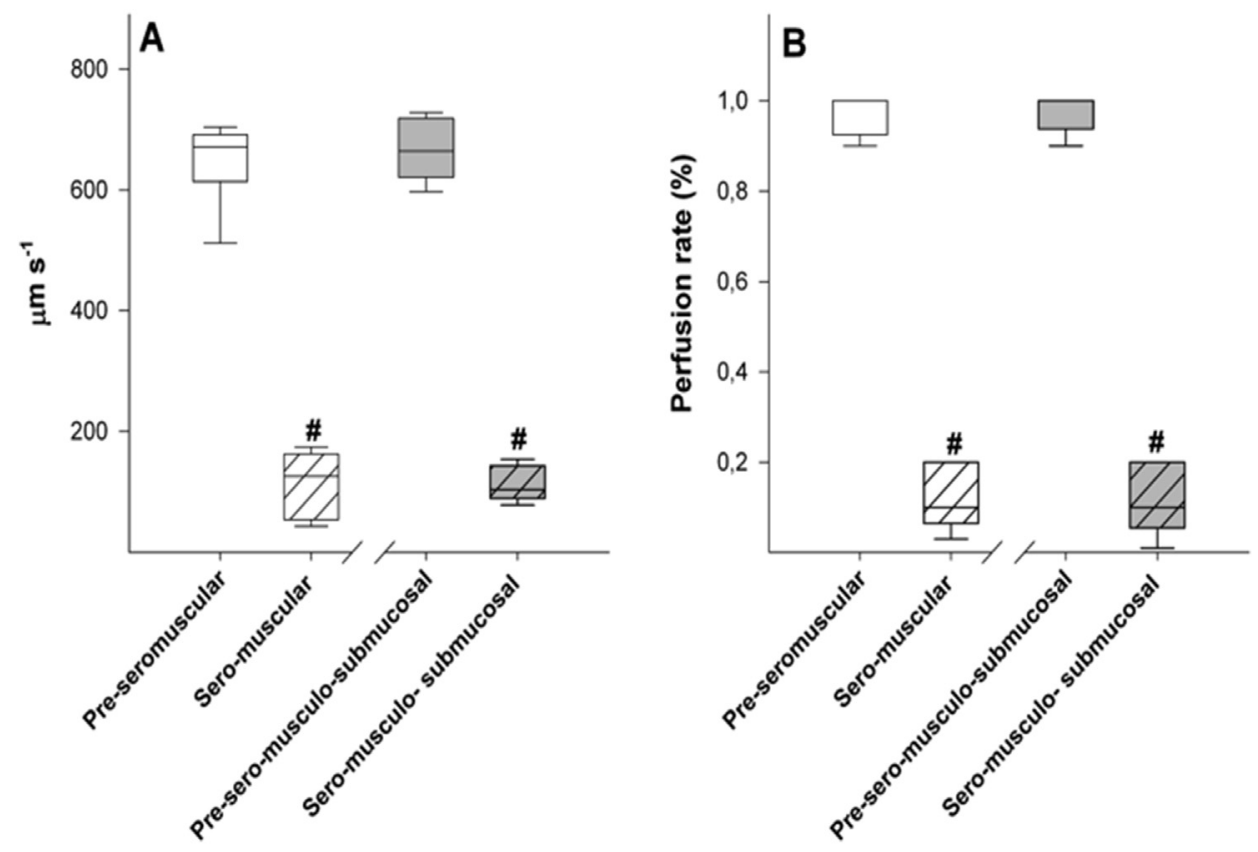

Figure 1 Changes in red blood cell velocity $(\mu \mathrm{m} / \mathrm{s})$ and perfusion rate (\%) in the control (grey empty box), sero-muscular (stripped white box) and sero-musculo-submucosal (checked white box) groups. The plots demonstrate the median (horizontal line in the box) and the 25th (lower whisker) and 75th (upper whisker) percentiles. ${ }^{\#} \mathrm{p}<0.05$ within groups before and after mucosectomy. 




Figure 2 The bladder augmented with reversed sero-musculo-submucosal ileal flap, the serosa facing inside before omentopexy (left). The contracted flap 8 weeks later after removal of the omentum (right).

contraction after mucosaectomy is the cuff stenosis that occurs after the Soave endorectal pull-through procedure for Hirschsprung disease, where submucosal dissection is carried out during the procedure [19]. Indeed, it is general practice to incise the residual seromuscular cuff, such is the regularity with which cuff contraction occurs.

In this study we used intravital videomicroscopy to monitor the microcirculation of the seromuscular ileal flaps in real time after mucosectomy. The two parameters (the velocity of the circulating red blood cells and the ratio of the open and closed capillaries) measured are widely accepted parameters to represent the patency of microcirculation [20-23]. These findings clearly indicate that mucosectomy with or without removal of the submucosa has major impact on the microcirculation of the residual flap. The incomplete circulatory cessation explains why acute necrosis and perforation was not present and why histology with light microscopy did not reveal thrombotic vessels in previous studies.

It has been observed that the branches of the vasa recta encircle the intestine and penetrate the muscle layers and form an arterial plexus within the submucosa. The vessels supplying the mucosal and muscular layers of the gastrointestinal tract originate from this plexus [24]. We propose that mucosectomy may disrupt fine vascular circuits within the intestine and the blood supply of the mucosectomized bowel may rely only on residual vessels originating directly from vasa recta. However, temporary ischemia-reperfusion caused by mucosectomy cannot be ruled out in the background.

One could claim that exposure of the serosa to urine could be responsible for contraction of the flaps and we should have used a control group with intact reversed flaps with no mucosectomy to assess this question. In a dog experiment, however, Cheng et al. [12] clearly showed that the serosal surface of the reversed ileal flaps become epithelized by urothelium and intact (full thickness) reversed flaps did not contract.

The application of intact (full thickness) reversed flaps is not ideal either, because the mucus produced by the intact flaps inside the peritoneum may result in intra-abdominal mucocele formation. Cheng et al. [12] reported moderate amounts of mucus pooled intra-abdominally 1 month after surgery in a dog. We also found a large mucocele perforating to the augmented bladder in one pig with full thickness (no mucosectomy) reverse ileal flap augmentation. The ileum flap however remained wide, that is no contraction was seen. To comply with our ethics approval (to keep the number of animals sacrificed as low as possible) we did not use more animals for full thickness reverse flap augmentation. Splints may have prevented flap contraction, but the pig bladders in our study were not drained for a long time, and the animals lost their urethral catheter within 7 postoperative days.

The omentum is known to be highly vascularized with microvascular endothelial cells and is composed mainly of adipocytes that produce an enormously high level of vascular endothelial growth factor [14]. Omentopexy has been used to facilitate revascularization of trachea grafts, myocardium, and even brain [15,16]; however, in our experiment it failed to recover the mucosectomized flaps. Revascularization from the omentum may require a longer period of time to occur and should precede the ischaemic event, which is obviously not possible in this situation.

In conclusion, this study provided direct evidence for the severely compromised microcirculation of the ileal flaps after experimental mucosectomy. The microcirculatory damage may be primarily responsible for flap contraction. This suggests that future research should focus on the preservation/restoration of the microcirculation during and after mucosectomy.

\section{Conflict of interest}

None.

\section{Funding}

The study supported by the Charitable Fund Manchester, the sponsor had no role in the study design, in the collection, analysis and interpretation of data; in the writing of the manuscript; and in the decision to submit the manuscript for publication. 


\section{References}

[1] Kropp BP, Cheng EY. Bladder augmentation: current and future techniques. In: Docimo SG, Canning DA, Khoury AE, editors. Clinical pediatric urology. London: Informa Healthcare; 2007. p. 871-910.

[2] Salle JL, Jednek R. Fibrosis of the seromuscular segment. In: Dewan P, Mitchell ME, editors. Bladder augmentation. London: Arnold; 2000. p. 80-1.

[3] Shoemaker WC. Reversed seromuscular grafts in urinary tract reconstruction. J Urol 1955;74:453-75.

[4] Shoemaker WC, Bower R, Long Jr DM. A new technique for bladder reconstruction. Surg Gynecol Obstet 1957;105: 645-50.

[5] Oesch I. Neourothelium in bladder augmentation. An experimental study in rats. Eur Urol 1988;14:328-9.

[6] Salle JL, Fraga JC, Lucib A, Lampertz M, Jobim G, Jobim G, et al. Seromuscular enterocystoplasty in dogs. J Urol 1990; 144:454-6.

[7] Motley RC, Montgomery BT, Zollman PE, Holley KE, Kramer SA. Augmentation cystoplasty utilizing de-epithelialized sigmoid colon: a preliminary study. J Urol 1990;143:1257-60.

[8] Salle JL, Homayoon K, Agarwal SK, Sanjiv K, Bagli DJ, Mclorie GA, et al. Determining factor in the contraction of deepithelialised gastric flap for bladder augmentation. J Urol 1997; 157:769A.

[9] Turner A, Subramanian R, Thomas DF, Hinley J, Abbas SK, Stahlschmidt J, et al. Transplantation of autologous differentiated urothelium in an experimental model of composite cystoplasty. Eur Urol 2011;59:447-54.

[10] Zhang Y, Liu G, Kropp BP. Re-epithelialization of demucosalized stomach patch with tissue-engineered urothelial mucosa combined with Botox A in bladder augmentation. BJU Int 2012;110:106-12.

[11] Hidas G, Lee HJ, Bahoric A, Kelly MS, Watts B, Liu Z, et al. Aerosol transfer of bladder urothelial and smooth muscle cells onto demucosalized colonic segments for bladder augmentation: in vivo, long term, and functional pilot study. J Pediatr Urol 2015;11. 260.e1-6.
[12] Cheng E, Rento R, Grayhack JT, Oyasu R, McVary KT. Reversed seromuscular flaps in the urinary tract in dogs. J Urol 1994; 152:2252-7.

[13] Masuda T, Furue M, Matsuda T. Novel strategy for soft tissue augmentation based on transplantation of fragmented omentum and preadipocytes. Tissue Eng 2004;10:1672-83.

[14] Xu L, Zhang S, Li J, Liu J, Liu H, Huang W, et al. Human tracheal allotransplant with greater omentum for revascularization. Exp Clin Transplant 2014;12:448-53.

[15] Kainuma S, Miyagawa S, Fukushima S, Pearson J, Chen YC, Sawa Y. Cell-sheet therapy with omentopexy promotes arteriogenesis and improves coronary circulation physiology in failing heart. Mol Ther 2015;23:374-86.

[16] Baaj AA, Agazzi S, Sayed ZA, Toledo M, Spetzler RF, van Loveren $\mathrm{H}$. Surgical management of moyamoya disease: a review. Neurosurg Focus 2009;26:E7.

[17] Shoji H, Yamaguchi N, Isomoto H, Minami H, Matsushima K, Akazawa Y, et al. Oral prednisolone and triamcinolone injection for gastric stricture after endoscopicsubmucosal dissection. Clin Endosc 2013;46:472-5.

[18] Kwon YH, Jeon SW, Lee JK. Endoscopic management of refractory benign colorectal strictures. Ann Transl Med 2014;22: 2305-839.

[19] Dasgupta R, Langer JC. Transanal pull-through for Hirschsprung disease. Semin Pediatr Surg 2005;14:64-71.

[20] Cerny CV, Turek Z, Par R. Orthogonal polarization spectral imaging. Physiol Res 2007:56:141-7.

[21] Cserni T, Takayasu H, Muzsnay Z, Varga G, Murphy F, Folaranmi SE, et al. New idea of intestinal lengthening and tailoring. Pediatr Surg Int 2011;27:1009-13.

[22] Cserni T, Cervellione RM, Hajnal D, Varga G, Kubiak R, Rakoczy G, et al. Alternative ileal flap for bladder augmentation if mesentery is short. J Ped Urol J Pediatr Urol 2015;11:64.

[23] Cervellione RM, Varga G, Hajnal D, Erces D, Kaszaki J, Harwood R, et al. Intestinal intramural vascular anastomoses. J Invest Surg 2015;14:1-6.

[24] Kvietys PR. Extramural blood and lymphatic vessels. In: Kvietys PR, editor. Gastrointestinal circulation. San Rafael: Morgan \& Claypool Life Sciences; 2010. 